\title{
The effect of random waypoint mobility infrastructure for wireless networks
}

\author{
Aseil nadhum kadhum \\ Aseel nadhum kadhum \\ College of Imam AL Kadhim (AS) Islamic Sciences // Babylon Branch \\ Easeel18@yahoo.com fatlawya@yahoo.com \\ Recived : $31 \backslash 1 \backslash 2017$ \\ Revised : 281512017 \\ Accepted : 211612017
}

\begin{abstract}
Mobile wireless sensor networks (mwsns) have as of late propelled a developing well known class of wsn in which portability assumes a key part in the execution of the application. As of late, portability has turned into an imperative zone of research for the wsn group. The expanding abilities and the diminishing expenses of portable sensors make versatile sensor systems conceivable and viable. In spite of the fact that wsn organizations were never imagined to be completely static, portability was at first viewed as having a few difficulties that should have been defeat, including availability, scope, and vitality utilization, among others. be that as it may, late studies have been indicating versatility in a more ideal light. In this article, an outline of proposition that assess portable correspondence in wsns is exhibited.

Accordingly , an assortment of versatility were proposed by analysts throughout the years where every portability display has its own particular properties that may influence the execution of the system in a way that varies from different models entitled with various properties. In this paper we give a study of versatility models that can be utilized as a part of remote sensor systems since it is imperative to give an arrangement of the accessible models along these lines a few portability models were looked into in the proposed work.
\end{abstract}

Key words : mwsns , mobility, Random, memory, AODV 


\section{INTRODUCTION}

Wireless sensor networks is remote sensor systems (WSNs) comprise of countless the nodes and little sensor hubs, which can be implanted in situations necessary. keeping in mind the end goal to finish a particular mission by measuring particular parameters, for example, weight or temperature. Therefore, WSN has turned into a crucial research region, because of their expansive possibilities in applications including non military personnel, mechanical, horticultural, and military applications. For a few applications, for example, military and modern, sensor systems are relied upon to work in apart situations for periods extending from days to years with no human intercession [1-7]. Since sensor hubs are battery controlled, restricted battery power and lifetime are fundamental test for these hubs. Therefore, many research thinks about proposed strategies intending to lateness the life time of sensor systems through diminishing the measure of vitality devoured by sensor hubs [8-12]. In addition, sensor hubs comprise of three subsystems, to be specific figuring subsystem, detecting subsystem and correspondence subsystem. As indicated by Patel et. al. [13] the vitality devoured by the correspondence subsystem is a few sizes higher than that devoured by the calculation subsystem and is subject to the transmission remove and weakening example. Therefore, to decrease the transmission remove, multibounce steering was acquainted with convey the detected information to the base station, on the grounds that the transmission separate for every hub is small than that required in single-jump. Then again, higher postponement is presented by multi-jump directing when contrasted with single-bounce. Along these lines, the achievement rate of the system will be influenced. In this manner, to take care of the previously mentioned issues i.e. constrained lifetime of sensor hubs and long postpones while presenting multi-bounce steering, analysts have presented the utilization of portable hub or hubs in WSNs. Consequently, these versatile hub or hubs can be utilized to gather information from static sensor hubs in this manner, diminishing the measure of vitality required in transmission by static sensor hubs.

\section{1- MOBILITY MODELS}

Portability models speak to the development of versatile sensors, and how their area, speed and increasing speed change after some time. Since portability examples may assume a huge part in deciding the convention execution, it is attractive for versatility models to copy the development example of focused genuine applications sensibly. Such models are regularly utilized for reproduction purposes when new correspondence or route procedures are explored. Versatility administration plans for portable correspondence frameworks make utilization of portability models for foreseeing future client positions[5]. A versatility model It must seek to simulate real developments phones axes. Changes in speed and, of course, needs to happen, and it should happen in vacancies reasonable schedule. For example, we would not need multiple stations to go in straight lines at a constant speed, since genuine portable hubs would not go in such a confined way. In this area, distinctive sorts of versatility models are depicted .

Versatility models essentially are of four sorts :

\subsection{Random Way Point Mobility Model}

Random waypoint mobility model is a variety of random walk show with spatial dependence[10]. It includes a stop times of change in the case, as well as speed. Knot Mobile (MN) is still in one area for a specific period of time (rest period), then the MN chooses the point of irregular $(x, y)$ in a renewal with the parameters area, for example, between the speed of $[0, \mathrm{VMAX}]$, the time delay between the [Pmin, Pmax] that are published continuously. $\mathrm{MN}$ and then go in the direction of the target picked up recently at the speed chosen. Upon entering, $\mathrm{MN}$ of stops a predefined day and age before beginning the procedure once more. The estimation of stops and speeds is pertinent. Quick hubs and long delays deliver a more steady system than moderate hubs and short stops. The most contended issue is that hubs will probably be in the focal part of the topology as opposed to near the limits [9]. Despite the fact that the Random Waypoint model is normally utilized as a part of recreation studies, a key comprehension of its hypothetical attributes is as yet inadequate. Right now, specialists are exploring its stochastic properties, for example, likelihood dissemination of move length and move time for every age. 


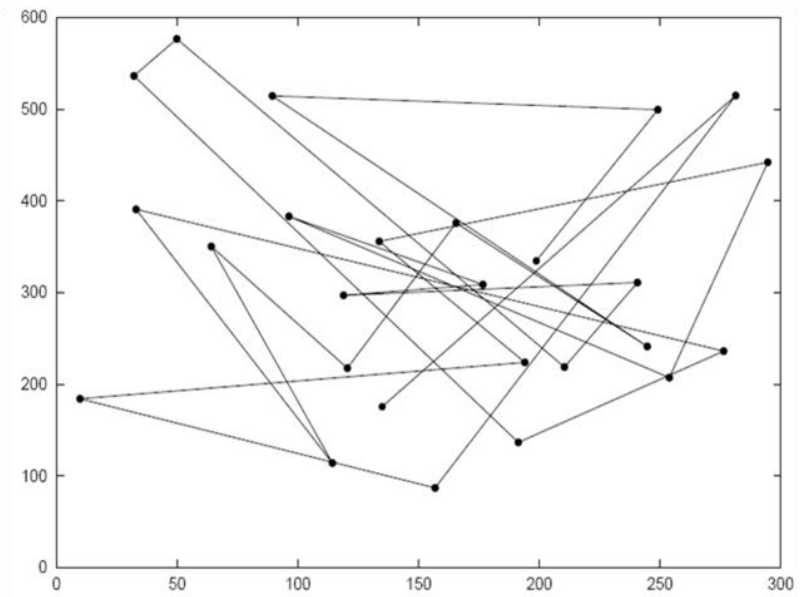

Figure1 node movement in the Random Waypoint Model

This model is a memory less portability prepare Where you are not using the data from the last state to choose the future. This is the state, and the current speed is independent with the last speed and the speed in the future is also for free with present speed.

- A complex relationship between node speed and pause time.

- A scenario with slow MNs and long pause times actually produces a more stable network than a scenario with fast MNs and shorter pause times.

- If the Random Waypoint Mobility Model is used in a performance evaluation, appropriate parameters need to be evaluated.

With such slow speeds, and large pause times, the network topology hardly changes.

\subsection{Pathway Mobility Model}

One obvious approach for integrating geographic imperatives in the form of multi-axis is limited to the development of trails in the directory. Advance and specific evidence in the field of cloning. Tian, Hahner and Baker et al.[12] use an arbitrary diagram to show the guide of city. This diagram can be either arbitrarily created or deliberately characterized in light of certain guide of a genuine city.

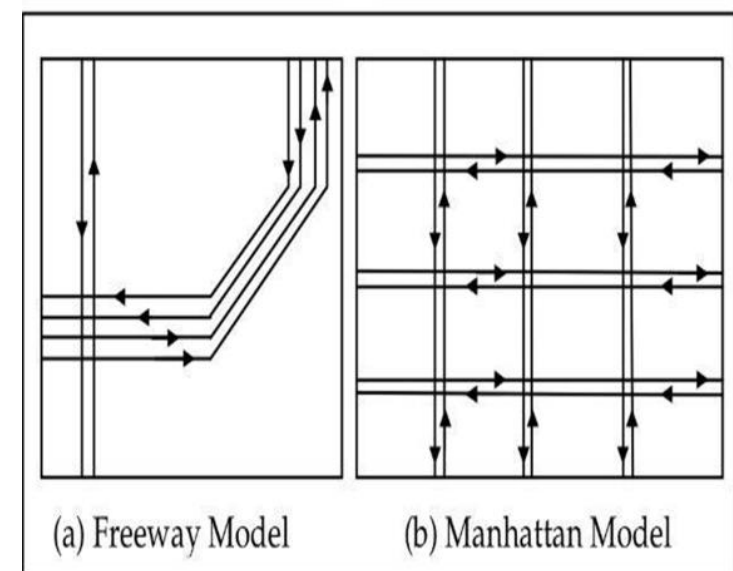

Figure 2 Freeway and Manhattan model in pathway mobility

At that point for every hub a goal is arbitrarily picked and the hub moves towards this goal through the most brief way along the edges. Upon landing, the hub stops for $\mathrm{T}$ pause over and over picks another goal for the following development. This system is rehashed Until the end of entertainment. Different from the show random way point where the axes can move openly, multiple axes in this model only allowed to go in the corridors. Whatever the case, since the selection is the goal of every arbitrary movement of the stage, a certain level of irregularity still exists to this model. Thus, in this scheme of multiple basis to prove, axes moving in the form of semi-arbitrary paths. By contrast, in this exhibition portability, [10] versatility Manhattan proving step in a fixed or vertical in the region address. This uses probabilistic approach in determining the axes developments as every transit point, the focus can move left or right, or directly in the same item. The possibility of taking the left turn is a half and it is right turnis $1 / 4$ each case. It allows versatile axis to move along the network level and the way in vertical territory.

\subsection{Gauss Markov Mobility Model}

The mobility of the center may be forced and constrained by physical laws to increase the speed, and the speed and the rate of the altar of the course. From now on, the current speed of the versatile center may depend on the for past speed. In this way the speeds of single hub at various schedule openings are "associated" 

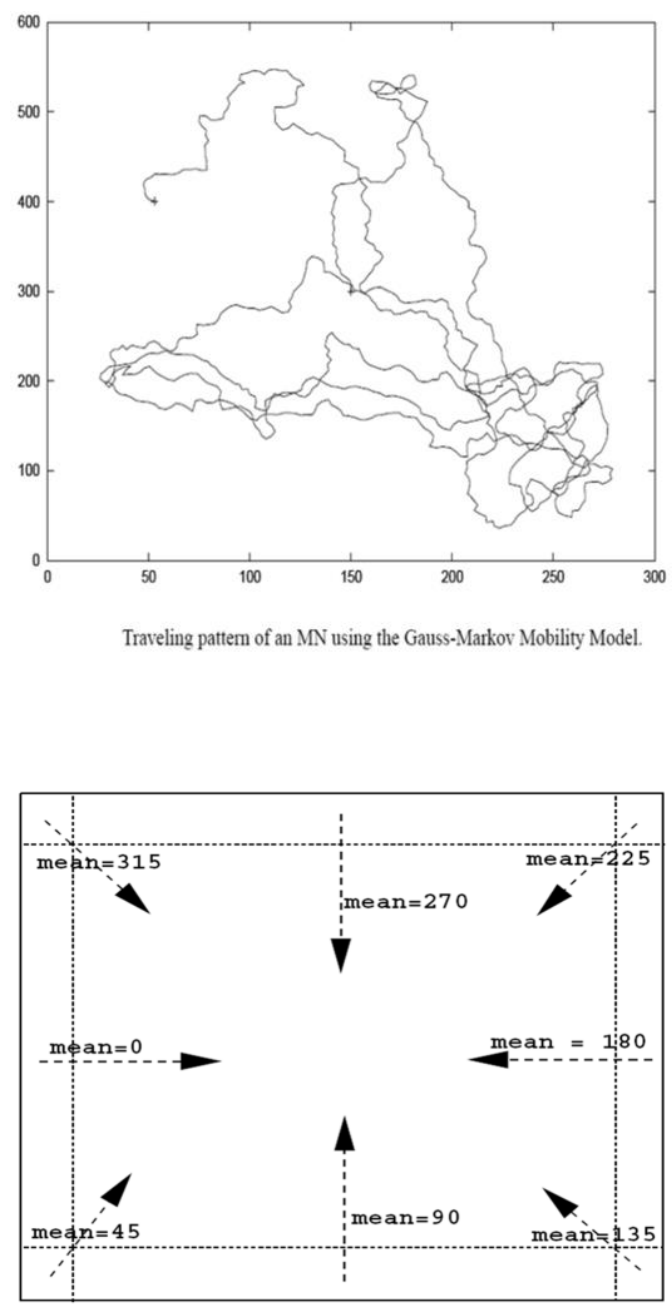

Change of Mean Angle Near the Edges (in degrees)

Figure 3 Traveling pattern of Mobile node using the Gauss Markov -Mobility Model

However, the memory less nature of Random Walk display, Random Waypoint demonstrate and different variations render them insufficient to catch this worldly reliance conduct. In the Gauss-Markov demonstrate, the transient reliance assumes a key part in deciding the portability conduct $[11,12]$. This model has a fleeting memory dependence with $\alpha$ level parameter. $\alpha$ is a parameter to reflect the erratic deal with the GaussMarkov. It is believed that the axis speed versatile to be associated After some time, and proved as a process Markov Gaussian stochastic indicator. When you reach the point hub will go past the limits of the recreation field, the heading of development is forced to flip 180 degree to remain within the simulation field [13].

\subsection{Random Point Group Mobility Model}

This model shows the spatial dependence. This model consists of clusters of themes that work is useful. Each grouping has a leading rafting, and a number of individuals. The development of leading gathering decides to conduct viability of the whole collection. Leading the movement gathered at time $t$ spoken by the carrier Vermont every member of this assembly that derailed this year Vermont Transmission by some degree. Each axis, and is set to portability with a reference point takes after the gathering development. The irregular movement is free disseminated arbitrary process whose length is consistently conveyed in the interim [0,rmax] where rmax is most extreme permitted remove deviation and the heading is consistently dispersed in the interim $[0,2 \pi)$. Since the gathering pioneer primarily chooses the versatility of gathering individuals, amass portability example is relied upon to have high spatial reliance for little estimations of speed and point deviation proportion[13].

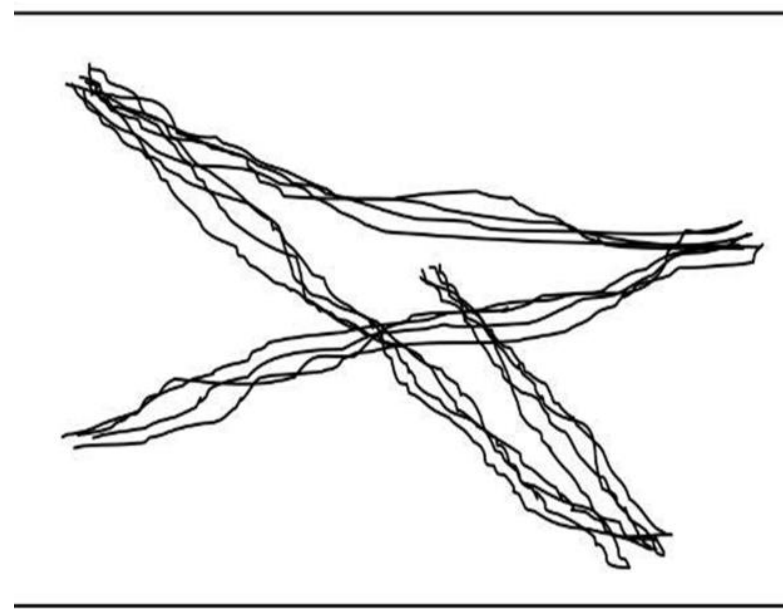

\section{Figure 4 Traveling pattern of one group ( four mobile nodes ) using the RPGM}

The whole field is partitioned into a few contiguous districts. Every area is solely possessed by a solitary gathering. One such case is front line correspondence. Diverse gatherings with various assignments go on a similar field in a covering way. Fiasco alleviation is a decent illustration: 
TABLE 1

THE CHARACTERISTICS OF MOBILITY MODELS USED IN IMPORTANT FRAMEWORK

\begin{tabular}{|c|c|c|c|}
\hline & Temporal & Spatial & geographic \\
\hline $\begin{array}{c}\text { Random } \\
\text { waypoint model }\end{array}$ & No & No & No \\
\hline $\begin{array}{c}\text { Freeway } \\
\text { mobility model }\end{array}$ & Yes & Yes & Yes \\
\hline $\begin{array}{c}\text { Manhattan } \\
\text { mobility model }\end{array}$ & Yes & No & Yes \\
\hline $\begin{array}{c}\text { Gauss markov } \\
\text { mobility model }\end{array}$ & No & No & No \\
\hline $\begin{array}{c}\text { Random point } \\
\text { group mobility } \\
\text { model }\end{array}$ & No & Yes & No \\
\hline
\end{tabular}

Reference point bunch versatility show

The gathering versatility show we proposed here is called Reference Point Group Mobility (RPGM) demonstrate. Every gathering has a sensible "focus". The inside's movement characterizes the whole gathering's movement conduct, including area, speed, bearing, quickening, and so on.. Consequently, the gathering direction is controlled by giving a way to the middle. As a rule, hubs are consistently conveyed inside the geographic extent of a gathering. To hub, each is alloted a reference point which takes after the gathering development. A hub is arbitrarily set in the area of its reference point ateach step. The reference point plot permits autonomous arbitrary movement conduct for every hub, notwithstanding the gathering movement model.

.Figure 1 gives a case of a two-group Every gathering has a gathering movement vector $\mathrm{v} \_g i^{\wedge} \leftarrow$. The figure likewise gives a delineation of how a hub moves from time tick $\tau$ To $1+\tau$.

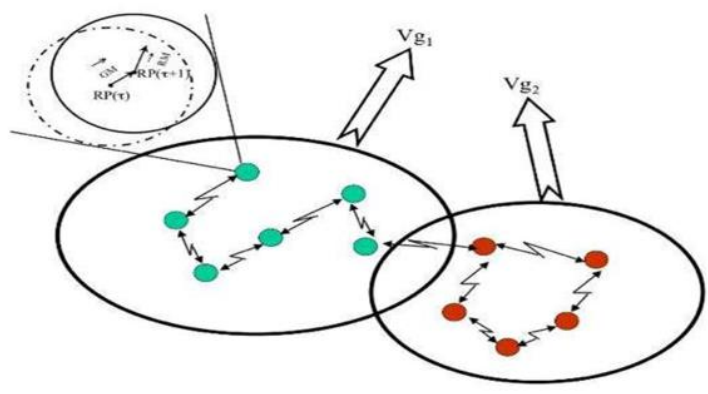

Figure 5 Group Mobility Model

\subsubsection{Various Applications of the Reference Point Group Mobility Model}

By appropriate selection of the road checkpoint and start collecting and parameters in the display area RPGM, is anything but it is difficult to show a different susceptibility applications. In this part, we use the demarcation RPGM agent in a few cases. The main model is to show the ground segment (see Figure 6). The whole region is isolated to a few nearby places, with an alternative gathering in each region. The model can be used to show the envelope a war zone, where the distinctive units are doing the same operations (for example, up to investigate the mine) in different bands. Each pool is responsible for one part. Another application could be expansive scale calamity recuperation, where diverse paramedic, police, fire fighters groups work in isolated neighborhoods. We call this model an

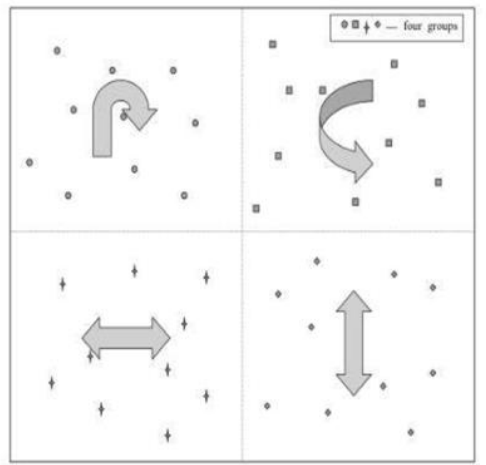

Figure 6 In-Place Mobility Model 
In-Place Group Model. Figure 6 gives a case of four gatherings working in four adjoining regions, with various movement designs.

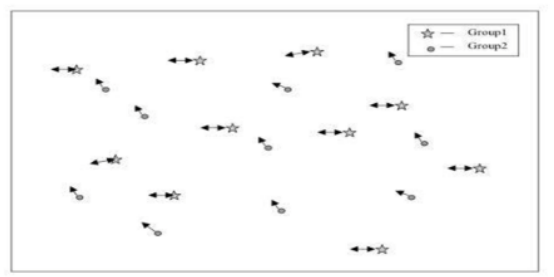

Figure 7 Overlap Mobility Model

The second model portrays a covered operation. Distinctive gatherings do diverse errands over a similar zone. Be that as it may, the particular necessities of every assignment make their portability design very unique. For instance, in a fiasco recuperation territory, the protect group, the therapeutic associate group and the clinician group will be arbitrarily spread out over the zone. However, every gathering has a one of a kind movement design, speed, scope and so on.. In Figure 7, there are two gatherings working in a similar region. We call this model the Overlap Mobility Model.

\subsubsection{Simulation Results:}

Figure 8 demonstrates the consequence of the connection up/down examination. At the point when portability builds, every one of the models demonstrate an expansion in the connection up/down rate. Not surprisingly, the irregular portability display It has the highest rate of change connection from the collection of biological samples. It indicates the Model Convention trivial change connection rate, since the introduction of four bouquets moving gradually. Model in place and have overlapping model diverse movement designs, yet they have comparable connection change rates[13].

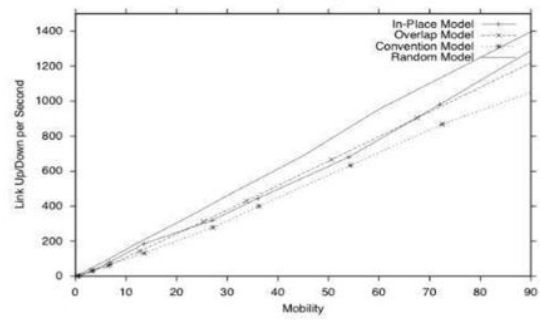

Figure 8 Link Up/Down vs. Mobility

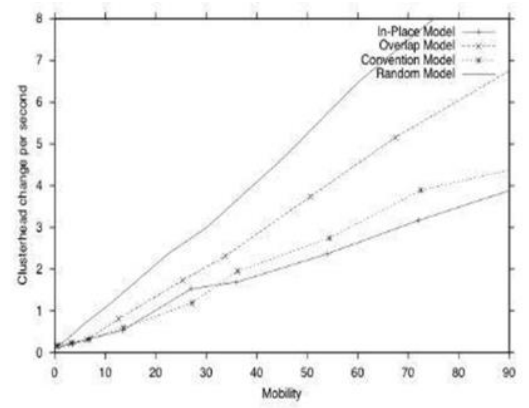

Figure 9 Clusterhead Changing vs. Mobility

And emerged as a result of the rate of change in the head group in Figure 9. Figure 9, we can see that random prowess prove to have a change, a higher proportion of samples collecting portability officially considered it at the top / bottom of the test connection. However, for this collection of different susceptibility patterns can affect the rate of change effectsly situation. The rate of overlap model is much higher than in the model in place and Model Convention. As shown on the photograph overlap typical model, many of the gatherings (four communities in the reenactment) have exercises in a similar field. Therefore, the mixing of four gatherings creates a more open doors for group redecision (review that the bunch head is the hub with most reduced id among its neighbors [9]). Oppositely, the In Place Model just permits every gathering to move inside its own geological range, with less group change openings.

\section{A Boundless Simulation Area:}

- A relationship between the previous direction of travel and velocity of an MN with its current direction of travel and velocity exists.

Steps according to the following formulas:

$$
\begin{gathered}
v(t+\Delta t)=\min \left[\max (v(t)+\Delta v, 0), V_{\max }\right] ; \\
\theta(t+\Delta t)=\theta(t)+\Delta \theta ; \\
x(t+\Delta t)=x(t)+v(t) * \cos \theta(t) ; \\
y(t+\Delta t)=y(t)+v(t) * \sin \theta(t) ;
\end{gathered}
$$


- The Boundless Simulation Area Mobility Model is also different in how the boundary of a simulation area is handled.

- MNs that reach one side of the simulation area continue traveling and reappear on the opposite side of the simulation area.

- Create a torus-shaped simulation.(Unobstructed)

- The rectangular area $->$ torus shape.

- The triangles illustrate when the $\mathrm{MN}$ reaches a boundary, and the dots illustrate where the $\mathrm{MN}$ reappears.

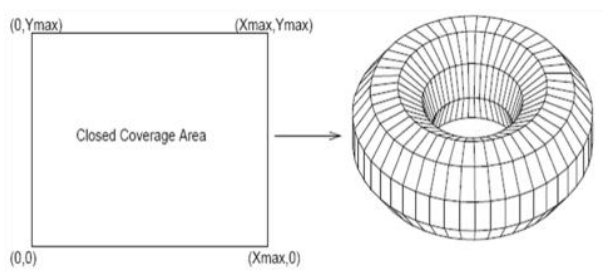

: Rectangular simulation area mapped to a torus in the Boundless Simulation Area Mobility Model.

Figure 9

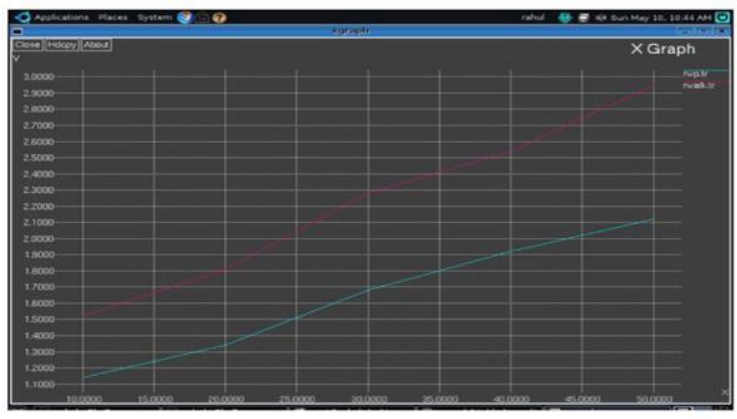

Figure 10 : average number of hops vs. number of nodes

This by Use the $\mathrm{x}$ graphic software.

\section{Conclusion}

In this paper we proposed collecting prowess to prove - Display reference point mobility group. Model sorted hosts diverse communities as cohesive in their prayers. Reenactment comes to prove that the decision to offer the ability to have any kind of impact in the flow of the physical connection and security package. Random model creates higher than the rate of progress in the availability of the collection of models. Moreover, random, and overlapping models cause for further mixing (other collection models) In this way, more changes head of the bunch. Moreover, the unique leadership conventions have different responses to transport models. In AODV and HSR when intersections are limited within the range of rafting, moving from forward speed. DSDV, then again, refers affectability little ability to collect and limited intersections. These results demonstrate that when it is sent to a specially designated system in real circumstances, it is not enough to test it with a walk arbitrary scalability type models since example movement can interact in a largely positive, but sometimes negative path with the system conventions. In addition to early work in a small number of titles. And tried multicasting agreements, because they remain for a greater impact of the collection of portability. House agent plans and strategies resources affected by the discovery of addition by collecting diversity. You must examine the impact of the movement on the spread of the channel (through the use of an appropriate spread of radio models) keeping in mind the ultimate goal to get practical match with a real proving ground tests. After a long wait, and models of landscapes (cliffs and waterways, highways and urban streets, structures, and forms an integral part in enclosed places, and so on.) Must be represented in that they both force the developments and the impact on the spread of models. 


\section{References :}

[1] R. Bagrodia and W. Liao. Maisie: A language for the design of efficient discrete-event simulations. IEEE Transactions on Software Engineering, 20(4):225-238, 1994.

[2] A. Bar-Noy, I. Kessler, and M. Sidi. Mobile users: to update or not to update? In Proc. of INFOCOM'94 Conference on Computer Communications, pages 570576, 1994.

[3] S. Basagni, I. Chlamtac, V. R. Syrotiuk, and B. A. Woodward. A distance routing effect algorithm for mobility (DREAM). In ACM/IEEE International Conference on Mobile Computing and Networking (Mobicom98), pages 76-84, 1998.

[4] P. Nain, D. Towsley, B. Liu, and Z. Liu, "Properties of Random Direction Models," INRIA technical report RR-5284,July 2004

[5] J. Broch, D. A. Maltz, D. B. Johnson, Y.-C. Hu, and J. Jetcheva. A performance comparison of multi-hop wireless ad hoc network routing protocols. In ACM/IEEE International Conference on Mobile Computing and Networking (Mobicom98), pages 8597, 1998.

[6] C.-C. Chiang. Wireless Network Multicasting . PhD dissertation, University of California, Los Angeles, Department of Computer Science, May 1998.
[7] S. Das, R. Castaneda, J. Yan, and R. Sengupta. Comparative performance evaluation of routing protocols for mobile, ad hoc networks. In 7th Int. Conf. on Computer Communications and Networks (IC3N), pages 153-161, October 1998.

[8] C. E. Perkins and P. Bhagwat. Highly dynamic destinationsequenced distance-vector routing(DSDV) for mobile computers. In ACM SIGCOMM , pages 234-244, 1994.

[9] D. B. Johnson and D. A. Maltz. Dynamic Source Routing in ad hoc wireless networks. Kluwer Academic Publishers, 1996.

[10] M. Gerla and J. T.-C. Tsai. Multicluster, mobile, multimedia radio network. ACM/Baltzer Journal of Wireless Networks ,1(3):255-265, 1995.

[11] C.-C. Chiang. Wireless Network Multicasting . PhD dissertation, University of California, Los Angeles, Department of Computer Science, May 1998.

[12] J. Li, P. Mohapatra," Analytical modeling and mitig ation techniques for the energy hole problem in sensor networks" Pervasi ve Mob. Comput., 3(3), pp. 233-254, 2007.

[13] Radhika Ranjan Roy United Stats Army Research Development and Engineering Commend(RDECOM) Myer Center 2700 Fort Monmouth,NJ 07703,USA rroy3@optonline.net 2007 


\title{
تأثثير البنية التحتية لإحداثيات التثقل العثوائي للشبكات اللاسلكية
}

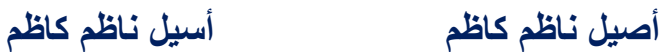

كلية الإمام الكاظم ألجامعه (ع) للعلوم الإنسانية / فرع بابل

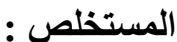

أطلقت شبكات المحمول لاستشعار ات اللاسلكية مجمو عة مهمة من هذه الاستشعار ات التي تؤدي فيها

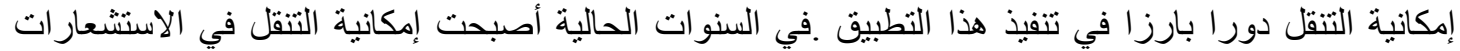

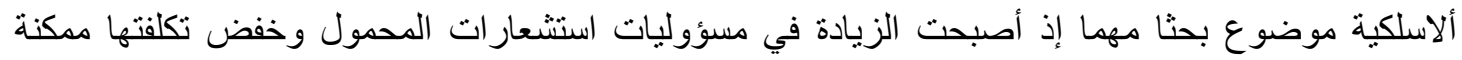

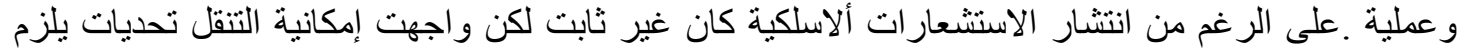

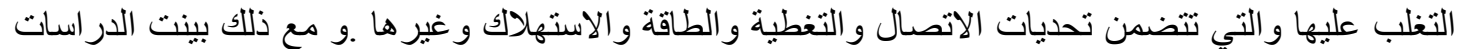

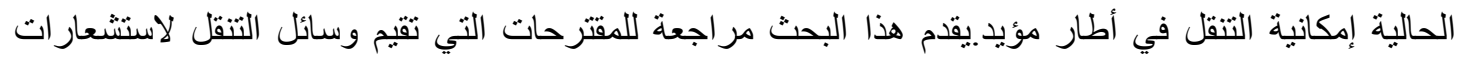
اللاسلكية ونتيجة لذللك قدم الباحثون و على مختلف السنوات مجموعة منوعة لإمكانية التنقل حيث لكل حركة لإنة

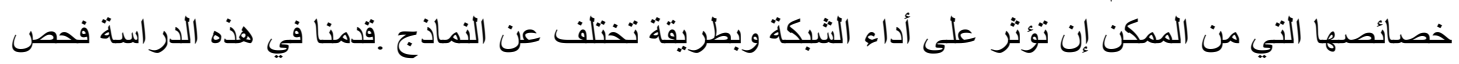
لنماذج إمكانية التنقل التي تنتعمل في شبكات الاستشعار ات اللاسلكية إذ تعتبر مهمة لأنها تقدم تصنيفا للنماذج المتوفرة ولذللك استعرضت هذه الدر اسة نماذج متعددة.

الكلمات المفتاحية:AODV , الذاكرة , العشو ائي ,التنقل , Mwsns 